\title{
Uncovering Embedded Face Threat Mitigation in Landscape Architecture Critique Feedback
}

\begin{abstract}
Amy L. Housley Gaffney
Abstract: Receiving public feedback on academic work may threaten students' face, particularly when such feedback is critical. One way that feedback may be cushioned is through face-threat mitigation techniques. I analyzed the use of such techniques in the feedback given by faculty and professionals to landscape architecture students as preparation for integrating communication instruction into these courses. This analysis revealed that informal language was the most prevalent technique employed by both faculty and professionals. Findings also indicated that faculty offered more direct advice to students than professionals, potentially fulfilling students' desires for relevant feedback. The marked differences between faculty and professionals patterns point to different interpretations of and goals in providing feedback. The analysis concludes with a discussion of this study's implications for future research on feedback.
\end{abstract}

Keywords: feedback intervention theory; face threat; communication across the curriculum; classroom feedback.

Although college students give presentations in a variety of classes, students in landscape architecture and related design classes give presentations as a central part of their learning experience (Anthony, 1991). In studio courses-usually taken each semester-students give multiple presentations and receive feedback immediately after presenting their design projects. Feedback can focus on the design or on students' presentations, with the emphasis typically on the former. Students find design critiques daunting for a variety of reasons, including a lack of instruction on how to communicate effectively in these settings (e.g., Anthony, 1991; Oak, 2000). Instruction implemented in this setting is typically vague and generalized (e.g., prepare, dress professionally; Anthony, 1991) rather than emphasizing the unique communication competencies required of students in design: transparent advocacy of the design's intent, management of interactions, demonstration of design evolution, explanation of visuals, and the credible staging of the performance (Authors, 2008).

Students perceive these critiques to be a rite of passage as well as a stressful, often traumatic, experience. Although the nature of the feedback can vary greatly across classes (Dannels \& Norris Martin, 2008), students report that they are not getting the feedback they desire, which is relevant, suggestive, balanced, engaged, considerate, and consistent (Authors, 2011). Research on feedback in the classroom points to the need for feedback to be tailored specifically to learning goals while providing specificity for students (Hattie \& Timperley, 2007). While grades are one indicator to students of success, faculty provide feedback in other ways, particularly in design classes where presentations are followed by questions and critique (Anthony, 1991). This verbal feedback is often unable to be captured in research studies about feedback (e.g., Basey, Maines, \& Francis, 2014). 
In order to delve into the feedback that students do receive, I examined the techniques that faculty members and industry professionals employ when providing feedback to landscape architecture students. My role in these classes was as communication scholar engaged in communication-in-the-disciplines (Dannels, 2001) work. With the goal of being able to provide effective instruction to design students on how to improve their communication, I sought to better understand the norms that were developed within these classes. In order to better understand the feedback that students received and why there may be a disconnect from what students desire (e.g., Authors, 2011), I analyzed verbal feedback given to one class of students. In doing so, I framed this work within the growing body of research focused on face threat mitigation in the classroom (e.g., Kerssen-Griep, Trees, \& Hess, 2008; Kerssen-Griep \& Witt, 2012; Witt \& Kerssen-Griep, 2011). Ultimately, these results point to the natural diversity in how feedback is approached, raising further questions about how to best harness the ability of the feedback to benefit students.

\section{Feedback Intervention Theory}

In comparison to the wealth of research about grading - the most common form of academic feedback - research on instructors' oral feedback is relatively sparse. One exception is Kluger and DeNisi's (1996) feedback intervention theory (FIT), which provides a framework for understanding how feedback is received, processed, and utilized, although the theory does not require feedback to be oral. Feedback interventions are "actions taken by (an) external agent(s) to provide information regarding some aspect(s) of one’s task performance” (Kluger \& DeNisi 1996, p. 255). In the case of critiques, those actions are verbal comments and the external agents are instructors and professionals from the community. Students compare their performance (based on feedback) to standards or goals. Feedback interventions are particularly helpful for their ability to focus students' attention on different factors such as learning and meta-tasks. Kluger and DeNisi noted that feedback interventions are less successful when teachers focus students' attention on meta-task factors, which are personal and self-oriented. Instead, they argue, cues focused on tasks such as learning and motivation lead to more successful results, as students are less likely to focus negative attention on themselves.

Expansions on FIT indicate that students look for particular characteristics in the feedback that they receive (e.g., King, Schrodt, \& Weisel, 2009), supporting students' valuing of task cues as described by Kluger and DeNisi (1996). Students make sense of instructor feedback based on utility, confidentiality, sensitivity, and retention (King et al., 2009). The most successful interventions provide useful advice and are private, nonthreatening, and memorable. Additionally, feedback utility and retention are associated with student affect for the class, which suggests the value in fair, task-oriented feedback. The delivery of the feedback makes a difference; specifically, student attributions of instructor credibility are influenced by instructors' use of face-threat mitigation techniques (Witt \& Kerssen-Griep, 2011).

Students understand feedback differently based on processing filters (detection, internal attributions, and defense mechanisms; King \& Young, 2002) and on timing. As Hattie and Timperley (2007) note, "it is necessary to consider the nature of the feedback, the timing, and how a student "receives" this feedback" (p. 101). Immediate feedback is more likely to improve unconscious or natural behaviors (e.g., eye contact) while delayed feedback is more likely to improve deliberative behaviors (King, Young, \& Behnke, 2000). Thus, in order for feedback to be successful, students must understand that feedback is taking place and be unlikely to become defensive. Finally, the levels of sensitivity that students bring to the feedback intervention affect how they interpret the feedback (King \& Young, 2002). Smith and King (2004) found that people

Journal of the Scholarship of Teaching and Learning, Vol. 15, No. 4, August, 2015. Josotl.Indiana.edu 
who were highly sensitive to feedback responded more positively to tactful, low intensity messages compared to direct feedback that turned attention inward. Thus, feedback efficacy can be improved by not only timing the feedback appropriately, but also adjusting the level of intensity for each student.

\section{Face-Threat Mitigation}

Although feedback is a complex educational communication event and a place where students' interpretations of feedback can vary greatly, faculty can control key characteristics of feedback. Faculty can integrate facework and face-threat mitigation (FTM) techniques (e.g., Kerssen-Griep, Hess, \&Trees, 2003; Wang et al., 2008) into their feedback in order to increase the chances of students accepting and utilizing the feedback.

Face, the image that one projects of oneself, consists of both positive face and negative face. Positive face is the desire to be liked and admired, while negative face deals with the desire to be autonomous (Brown \& Levinson, 1987); when these desires are threatened, people may engage in facework. These facework actions can be focused on tact (respecting the other's autonomy), solidarity (accepting the other as part of a group), or approbation (emphasizing the positive over negative). Face threats can vary in terms of how they are interpreted, based on factors such as context and prior experiences (Wilson, Kim, \& Meischke, 1991), as well as the nature and context of relationships (Arundale, 2006; Locher \& Watts, 2005) and culture (e.g., Merkin, 2006). In fact, much of the research on facework has centered on the impact of cultural characteristics on approaches to dealing with face threats; for example, Oetzel et al. (2001) compared China, Germany, Japan, and the United States, noting the strong connection between cultural components and facework.

FTM techniques are utilized in a variety of settings beyond the college classroom. For example, Harrison and Barlow (2009) found that arthritis patients taking part in an online program relied heavily on indirect comments and suggestions (e.g., personal narratives that related to advisees' situations), suggesting that polite strategies are useful for preserving both positive face of the speaker and the negative face (i.e., autonomy) of those receiving feedback or advice. Similarly, Vásquez (2009) found that teachers experiencing difficulties at work used indirect strategies and contradicting statements to avoid making official complaints or seeming too concerned in front of their employers. Instructors might attempt to save the positive and negative face of their students through tactics such as shifting attention (Pickford, 2008) and exhibiting politeness (Wang et al., 2008). Using politeness strategies in communicating with students is correlated with positive learning outcomes (e.g., Pickford, 2008; Wang et al., 2008), motivation (Kerssen-Griep, 2001; Kerssen-Griep \& Witt, 2012), productivity (Kerssen-Griep et al., 2003), and student perceptions of a positive environment (Kerssen-Griep et al., 2008) with a fair and credible teacher (Kerssen-Griep \& Witt, 2012; Trees, Kerssen-Griep, \& Hess, 2009).

Feedback is a complex component of pre-professional programs, where students are introduced not only to the content of their discipline, but also to the types of professional cultures they are joining. Simulated workplaces for pre-professionals can introduce students to their chosen discipline, but at the same time, the academic culture tends to take precedence over the professional (e.g., Burnett, 1996; Dannels, 2000), due in large part to the classroom being "laden with situated, context-based complications” (Dannels, 2000, p. 8). The use of professionals as sources of feedback provides learning opportunities for students:

Journal of the Scholarship of Teaching and Learning, Vol. 15, No. 4, August, 2015. 
...employer assessment promotes evaluative reaction and enables students to develop and utilise criteria for evaluating the adequacy of their own understanding and performance-a crucial part of the metacognitive skills of the autonomous, effective learner. Employer involvement confers additional benefits: it makes learning more meaningful for the student, bringing a wealth of "real world experience" into the learning environment; it establishes credibility and reinforces the aims and objectives of the staff; it provides a motivational impetus raising the level of performance. (Laybourn et al., 2001, p. 368)

These benefits are most salient when feedback is presented in a manner that is fruitful for students. Design students voice discontent about the nature and content of feedback received from faculty and professionals (Authors, 2011). Understanding what politeness strategies are used in the feedback students receive may provide important insights into why students experience critiques negatively. If "the relationship between student and assessor is at the heart of a successful feedback process” (Price et al., 2010, p. 285), understanding feedback in the critique requires a distinction between the two main sources of feedback: professionals and faculty. Therefore, I pose the following research question:

RQ: In landscape architecture critiques, how do faculty members and professionals use face threat mitigation techniques?

\section{Method}

The data analyzed here came from a larger project focused on competent communication in design classes. Although my role was not as a traditional instructor of record, this project falls in the vein of other Scholarship of Teaching and Learning work (e.g., Defazio, Jones, Tennant, \& Hook, 2010) that are grounded in cross-curricular work. The videos used here came from a graduate-level course in landscape architecture at a large southeastern land grant university; the course was selected because the small enrollment allowed for substantial feedback time per student. Researchers video recorded students' presentations and the subsequent feedback session. This project centered on presentations given approximately one-third of the way through the semester; students gave their initial ideas about the semester-long project focused on redesigning a downtown site. Because these presentations were a checkpoint along the way to completing the full project, the session was predominately formative in nature, although presentations and projects were graded by the course professor. My role in this semester was as an observer in order to prepare for providing feedback; I provided instruction in the following semester.

Prior to the start of presentations, the 10 graduate students pinned drawings to the classroom in the College of Design. Students spoke for approximately 10 minutes (timed by the professor), then remained standing for a feedback and question session. The audience shifted chairs around to view each student's materials. Feedback time was planned at 10 minutes per student, although the actual time spent on feedback varied. The feedback and questions came from the audience of the class professor (female) and another faculty member in the department (male). Additionally, three local professionals took part in the critique at various points. These professionals held positions in local design firms and city planning. The total time recorded for both presentations and feedback was 232 minutes.

Before examining the feedback, I began by dividing the video files based on changes in speaker and disregarding any comments made by students. A notation was made of the speaker as

Journal of the Scholarship of Teaching and Learning, Vol. 15, No. 4, August, 2015. Josotl.Indiana.edu 
either faculty or professional. The data consisted of 227 comments, which varied in length and focus; division was based solely on speaker change. Initial definitions of eight FTM techniques were derived from previous work (Kerssen-Griep et al., 2003; Kerssen-Griep \& Witt, 2012). The initial wording of definitions was tested with a small sample of feedback that was not part of the final project. Two coders (myself and a research assistant) coded the samples, noting places where we were unclear about definitions and/or the appropriate coding of a piece of data. We continued in this manner until our coding was consistent and no further questions were raised. Throughout the coding, each segment had the possibility of containing more than one FTM technique, and not all segments contained FTM techniques. Table 1 presents the final definitions. The research assistant and I then took a random subset of the segments (approximately 20\%) and coded independently. Our responses were consistent, achieving Cohen's kappa scores ranging from .83 to 1.0 for the various techniques, which were all in the "very good" or higher range. Subsequently, all segments were coded by one researcher. 
Housley Gaffney, A.

Table 1

\section{Coding Definitions}

\begin{tabular}{|c|c|}
\hline Code & Definition \\
\hline $\begin{array}{l}\text { Complimentary } \\
\text { language }\end{array}$ & $\begin{array}{l}\text { Acknowledges and encourages positive student actions or ideas. Key words } \\
\text { might include: Good job, well done, I liked, etc. }\end{array}$ \\
\hline Humor & $\begin{array}{l}\text { Makes light of a situation or provides a funny personal example, which may } \\
\text { be appropriate (relevant to situation; not offensive) or inappropriate. } \\
\text { (irrelevant to the situation or offensive to the class). Humor does not need to } \\
\text { be acknowledged by audience. }\end{array}$ \\
\hline $\begin{array}{l}\text { In-group } \\
\text { language }\end{array}$ & $\begin{array}{l}\text { Indicates that the student is becoming a member of the same field or has } \\
\text { similar work ideals as the speaker. In-group may refer to class or to discipline. } \\
\text { Key words include: we, us, our field. }\end{array}$ \\
\hline $\begin{array}{l}\text { Informal } \\
\text { language }\end{array}$ & $\begin{array}{l}\text { Presents feedback conversationally, emphasizing interpersonal interactions. } \\
\text { Speakers might use more inflection when they provide informal feedback. }\end{array}$ \\
\hline Offers advice & $\begin{array}{l}\text { Suggests how a student should proceed with his or her project. Different from } \\
\text { a tactful hedge, in that the speaker encourages the student to follow his or her } \\
\text { specific advice. }\end{array}$ \\
\hline Self-disclosure & $\begin{array}{l}\text { Refers to a personal situation that might apply, mirror, or relate to a student's } \\
\text { project or situation; anecdotes, stories, and experiences. May be appropriate } \\
\text { to the situation or may be inappropriate (irrelevant or without potential to help } \\
\text { student) }\end{array}$ \\
\hline Solidarity & $\begin{array}{l}\text { Attempts to establish solidarity with the student by referring to shared } \\
\text { understanding of events or practices. }\end{array}$ \\
\hline Tactful hedge & $\begin{array}{l}\text { Gives advice or a suggestion in an indirect manner, suggesting that the student } \\
\text { could potentially think of other ways to solve the problem; advice might be } \\
\text { "hedged" between or after qualifying words (e.g., maybe, could, perhaps) that } \\
\text { indicate the student's autonomy. }\end{array}$ \\
\hline
\end{tabular}

For analysis, I first looked at the frequency with which different techniques occurred; proportions were calculated relative to the total number of techniques as well as to the total number of segments. For example, the number of instances of informal language was calculated as (1) a proportion of the total number of times I identified a technique being used and (2) a proportion of the number of segments. An overall comparison was made using a two-variable chi-square analysis (Frey, Botan, \& Kreps, 2000). Certain techniques that had a low frequency (humor, self-disclosure, and solidarity) were removed from the analysis because they violated the assumptions of the test. I used the two-variable chi-square analysis with specific techniques to determine which techniques were the largest contributors to the differences. 


\section{Results}

The overall picture of FTM technique use points to the prevalence of informal language, which appeared in 167 instances. The next most prominent forms of feedback were complimentary language (46 instances), tactful hedges (45 instances) and offering advice (45 instances). Faculty and professionals made a comparable number of comments (112 and 115 comments, respectively). However, faculty and professionals varied in the number of FTM techniques used (see Table 2). Of the total 321 instances of FTM techniques, professionals used 196 FTM techniques, which accounted for $61 \%$ of the total techniques used. Faculty, on the other hand, used 125 techniques, which accounted for $39 \%$ of the total techniques used. In another way to view the data, faculty had an average of 1.12 techniques per segment; and professionals had an average of 1.70 techniques per segment. Due to the limited frequency with which some techniques appeared, they were removed from the comparison analysis. Overall, faculty and professionals differed in their use of techniques, $x^{2}(4, \mathrm{~N}=321)=15.86, p<.01$.

Informal language was the most common technique used by both faculty and professionals. For example, one professional, in responding to a student's comments about the future of the site prefaced a comment by saying "I can see how, even if the city wasn't ready to rock and roll with the transportation...." Such a comment was labeled as informal because of the presence of a contraction and a colloquialism. Professionals did use informal language significantly more often in comparison to faculty, $\chi^{2}(1, \mathrm{~N}=159)=5.29, p<.05$.

Table 2

Techniques used by faculty and professionals as percentage of techniques and of segments.

\begin{tabular}{lrrrr}
\hline & \multicolumn{2}{c}{ Percent of Techniques } & \multicolumn{2}{c}{ Percent of Segments } \\
\cline { 2 - 5 } & \multicolumn{1}{c}{ Faculty } & Professional & Faculty & Professional \\
\hline Complimentary language & 9.60 & 17.35 & 10.71 & 29.57 \\
Humor & 0.80 & 0.51 & 0.89 & 0.87 \\
In-group language & 4.80 & 2.04 & 5.36 & 3.48 \\
Informal language & 52.00 & 47.96 & 58.04 & 81.74 \\
Offering advice & 20.00 & 10.20 & 22.32 & 17.39 \\
Self-disclosure & 1.60 & 2.55 & 1.79 & 4.35 \\
Solidarity message & 3.20 & 1.53 & 3.57 & 2.61 \\
Tactful hedges & 8.00 & 17.86 & 8.93 & 30.43 \\
\hline
\end{tabular}

While both faculty and professionals used informal language more than any other technique, the use of other techniques diverged. As a proportion of techniques, faculty offered advice more often than did professionals, although the difference between groups was not significant, $\chi^{2}(1, N=45)=0.56, p>.05$. For example, a faculty member told a female student:

Journal of the Scholarship of Teaching and Learning, Vol. 15, No. 4, August, 2015. Josotl.Indiana.edu 
I feel you have a strong idea for all this, but we have to really delve into more possible ideations or solutions to achieve that and be much more clear about how you are being driven to make those design decisions.

Complimentary language was used to preface the advice; specifically, the faculty member advised the student to generate more possibilities for the project and also to have a more specific articulation of why design choices were made.

Meanwhile, professionals used proportionally more tactful hedges, $\chi^{2}(1, N=45)=13.89$, $p<.001$. For example, after a female student answered questions about her choice of placement of train tracks relative to gathering areas, a professional commented "I think [the tracks] can be either a focus point or a real dividing line.” By prefacing her comment as such, she hedged the suggestion that followed. In response to another student, the same professional hedged an interpretation of the site: "I guess you're trying to make your site a source more than you are trying to draw from them” (emphasis added).

Professionals used complimentary language as a significantly higher proportion of techniques than did faculty, $\chi^{2}(1, N=46)=10.52, p<.01$. For example, one professional was complimentary of a female student's metaphor: "the idea of porosity and the capacity to absorb is really apt for a downtown of a city in general.” In stating this, the professional is providing positive reinforcement for the student's design choices. Later in the same comment, the professional referred to one of the student's choices as "a really good starting point."

In-group language was sparse, but did appear; faculty and professionals used this technique at approximately equal rates, $\chi^{2}(1, \mathrm{~N}=10)=0.4, p>.05$. An example of in-group language came in response to one student's description of her material study of cork, wherein she described the reactions of different liquids when applied to the porous material. The female professional responded to this student, who was the first in the class to present:

I don't know what everybody else did for their material studies, but the idea of porosity and the capacity to absorb is really apt for a downtown of a city in general... I guess the question for you guys as designers is how do you work with a more porous material so you can build more capacity. I think we'll all agree one of the goals was to encroach growth around it.

This professional identifies the students as part of the group of designers by referring to students as such, in addition to using first-person plural language ("we'll all agree”).

Because of the small number of occurrences of humor, self-disclosure, and solidarity, these techniques could not be statistically compared, although trends are informative. Humor showed up in only two places. In one comment to a pair of students, the male faculty member commented on the dramatic change seen in the students' projected image: “... although I think by the time you get to 25 years, it looks like the urbanization sort of takes over like a monster that's going to take over." This comment was punctuated by a "raar" sound and his hands creating a monster mouth. The comment seemed to be aimed at lightening the mood rather than directly criticizing the students' choices of how to present the projection.

The same professional who provided in-group language examples provided one of the few examples of self-disclosure; in this case, she was talking to the pair of students who presented together:

Journal of the Scholarship of Teaching and Learning, Vol. 15, No. 4, August, 2015. Josotl.Indiana.edu 
That helps clarify a lot because, again, what I've learned over the years is you can have the most ecologically sound design you want your client to take, but at the end of the day, time is money and if they have a timeline that is going to mean a return on investment, you're not going to convince them that the most natural, greenest, coolest thing you want to do is acceptable. [emphasis added]

Similarly, the professional provided one of only a handful of solidarity examples in responding to a student's thinking about where people will enter her site and the prioritizing of pedestrians versus vehicle traffic:

And that's frankly been a big change since the genesis of all these cities along the east coast and today.... When you want to locate a retail store, you look along the thoroughfare instead of in a district. So, the whole way we thought about sources has changed.

In this comment, the professional provides a sense of camaraderie with the student about the process of designing.

Together, these results point to different uses of face threat mitigation techniques by faculty and professionals, along with a clear preference for certain types of techniques. The implications of these results will be discussed in the next section.

\section{Discussion}

Critiques, as an instructional tool, are designed to provide students with an opportunity to garner feedback about their design projects. The feedback from faculty and professionals contains various efforts to mitigate face threats, but faculty and professionals utilized these opportunities differently. Most notably, the differences in what techniques were used points to different conceptualizations of the function of feedback.

The prevalence of FTM techniques in the feedback given during the critiques suggests that the critique is a productive environment for students. Kerssen-Griep et al. (2003) found that faculty use of facework predicted positive educational outcomes such as motivation and attentiveness. Although not every comment made by faculty and professionals incorporated FTM techniques, both groups averaged more than one technique per comment, with some comments containing three or more techniques. These rates suggest that faculty and professionals are both willing and able to utilize FTM techniques in their comments. Furthermore, the co-occurrences suggest facework that "sandwiches" direct advice between compliments or indirect comments.

However, faculty and professional use of FTM were markedly different, suggesting that faculty and professionals serve different purposes in the critique feedback. Given the shared expertise and interest in design, it is logical to anticipate a high rate of solidarity and in-group language. However, these techniques were actually fairly uncommon and were used more frequently by faculty than professionals. Faculty used informal language in more than half of their comments and offered advice in nearly a quarter of their comments. It is possible that faculty felt they were in a better position to offer advice than were professionals; alternatively, because faculty work closely with students throughout the semester, they did not feel the need to build rapport with students. For professionals, this critique was typically the first contact with students. This difference mirrors FIT in that instructors appeared to see the value of task-oriented feedback. These results paint a picture of how those professionals may function in critiques compared to faculty,

Journal of the Scholarship of Teaching and Learning, Vol. 15, No. 4, August, 2015. 
supporting the argument that students could benefit from having professionals give feedback (Laybourn et al., 2001).

Professionals used more FTM techniques and did more rapport building than did faculty. Furthermore, they used significantly more complimentary language, informal language, and tactful hedges, and had more co-occurrences of techniques. The professionals invited to critique students were local professionals who often employed this program's students and graduates; professionals may have be attending to this need to build positive relationships. Although indirect feedback might not be as immediately useful as direct advice, previous findings indicate positive implications for students who receive polite feedback (Wang et al., 2008).

FIT and FTM research demonstrates that individuals' characteristics will influence their perceptions of feedback. For example, individuals high in feedback sensitivity respond best to tactful, low intensity messages (Smith \& King, 2004). Students are most likely to benefit from feedback when they are not defensive (King \& Young, 2002), which the FTM techniques should help. At the same time, FIT (Kluger \& DeNisi, 1996) argues that mitigating face threats is important to helping students respond productively to feedback.

The use of FTM techniques in the design critiques studied here is likely intended to help students, although the efficacy of such feedback depends largely on the students receiving the comments. For example, research suggests that students can best make sense of instructor comments that offer useful advice in a private setting and that these messages should be nonthreatening and memorable (King et al., 2009). Design critiques are public events, and advice was not the most prevalent FTM used by faculty or professionals. The use of informal language might indicate an effort to make feedback nonthreatening and memorable. These patterns seem to indicate that, at least in terms of feedback content, faculty and professionals create an informal environment. Complicating the public nature of these critiques is that students are receiving feedback from superiors (faculty and professionals) but are in front of peers. Supervisors typically emphasize FTM less than people of lower status (Brown \& Levinson, 1987). Perhaps, then, faculty and professionals are somewhat cognizant of the complex situation wherein students are speaking in front of potential employers as well as peers.

\section{Students’ Desires Compared to Critics’ Feedback}

Although the focus here has been on the comments and not on students' reactions to the comments, the use of FTM techniques here can be aligned with what students in design courses previously reported as feedback that facilitates a learning climate (Authors, 2011). Students report desiring feedback that is relevant, suggestive, balanced, engaged, considerate, and consistent. At the same time, students often report that the critique is difficult, which may be symptomatic of mismatched expectations and reality.

The feedback patterns map onto students’ desires for feedback identified in Authors (2011). Informal language seems to align with students' hope for engaged and considerate feedback. Furthermore, students' desire for balanced feedback (not only positive or negative, but a variety of responses) could be at least partially met by faculty and professionals' use of complimentary language, with professionals using complimentary language in roughly one-third of their comments. At the same time, however, the prevalence of FTM techniques may have seemed overly positive to students. In the previous study, students expressed a desire for feedback to be engaged, considerate of the individual student, and balanced between positive and negative. Thus, the overabundance of informal language might seem to students to be inappropriate for the critique and for the relationship that exists between students and critics. This reliance on informal language 
could be problematic in the eyes of students, as such techniques sometimes involved faculty discussing subjects and issues that were only loosely related to students' projects, such as referencing activities or interests outside of the realm of landscape architecture. Furthermore, professionals consistently used hedges, which may have diluted the specific suggestions desired by students.

Solidarity, self-disclosure, and in-group language are feedback techniques that help mitigate face threats (e.g., Kerssen-Griep et al., 2003). At the same time, however, design students have expressed concern that feedback is not always relevant to the particular student and to that particular project (Authors, 2011). While the comments reflecting solidarity, self-disclosure, and in-group language may help students generally when it comes to feedback, the same comments may run counter to students' desired feedback. For example, in the earlier study, one student commented "when somebody doesn't even try to take the effort to understand what you are, what you're doing, that's just so shallow. They just don't really talk about the work” (p. 106). Whether professionals are engaging in FTM intentionally or not, students may see such attempts as detracting from the content of the critique.

The limited presence of solidarity and in-group language potentially indicates a desire from critics to maintain boundaries between professionals/faculty and students while also focusing more on feedback and advice. However, it is apparent that direct feedback was not the main goal for some critics (most likely in the interest of politeness), as demonstrated by the prevalence of tactful hedges and informal advice. Although being tactful and informal is important, perhaps there is an over-reliance on these techniques in critiques. Students may be disoriented when professionals are placing such a strong emphasis on mitigation techniques.

Students see critiques as a matter of survival and requiring of detachment, but also describe critiques as a process of collaboration that benefits from disclosures (Authors, 2011). Authors (2011) suggested that viewing feedback interventions as relational would allow a closer examination of how is interpreted by students. For example, the indirect advice and heavy uses of informal language exhibited in this study may have represented critics' attempts to engage in a collaborative, comfortable process with students. Ultimately, it is the students-as recipients of the feedback — who determine the success of the FTM techniques.

\section{Reflective Practice and Implications}

Previous literature has suggested that immediate feedback is most helpful for correcting behaviors while delayed feedback can lead to more substantive changes (e.g., King et al., 2000). The use of face threat mitigation techniques in these critiques seemed to be a form of lessening the blow of substantive feedback. In critiques, feedback is primarily immediate, which may be overwhelming to students. That is, students are likely to implement simple advice such as how large their photos should be in future presentations when it is offered during immediate feedback sessions. However, it is unclear whether students will be overwhelmed by suggestions to completely redesign key elements of their projects when such advice is offered immediately after their presentations. Thus, although FTM techniques may ease students, they may not be sufficient to help students deal with major feedback in an immediate, public setting. From the educational perspective, the prevalence of FTM techniques in an environment that is simultaneously considered overwhelmingly negative (e.g., Authors, 2011) points to the need to carefully consider both the use of FTM and the logistics of providing feedback (e.g., timing). As an outsider preparing to participate in this discourse community, I recognized that the structure (e.g., immediate feedback) may be out of my control but that I could, whenever possible, seek to utilize techniques 
that would make the feedback more useful. In future research, instructors should consider the literature on feedback intervention theory in business settings in order to gain further insights on best practices in coaching (e.g., Luthans \& Peterson, 2003)

Second, the varied use of FTM, particularly in light of politeness research that points to the lack of a need for faculty and professionals to use such techniques, suggests the need for a deeper look into why these FTM techniques were used and to what end in the minds of students. As noted earlier, students desire feedback that is relevant and applicable (Authors, 2011). Thus, it is possible that even well-intentioned FTM techniques might only result in higher student comfort levels rather than higher student engagement levels. Students generally desire feedback that explicitly suggests how to improve rather than simply a justification of a grade (Price et al., 2010). While the integration of such feedback may take time, the frequency with which FTM techniques did appear sets the stage for further integration. In future research, then, a potentially fruitful area is students' impressions of faculty and professionals' roles in the critique and the extent to which they desire feedback from professionals to be relational in nature.

Finally, although I focused specifically on a design course in this study, the nature of the feedback sessions is similar to other areas of academia, such as speech and art courses. Therefore, findings such as the amount of informal language used by faculty in landscape architecture critiques likely relate to the feedback sessions of other student presentation-oriented courses. Based on the aforementioned potential similarities, it is worth reiterating that faculty members offered more direct advice than professionals. Because outside professionals tend not to participate in feedback interventions in public speaking or education courses, these students might receive more direct and specific feedback than do students in design courses. Despite the potential benefit of receiving more direct advice, design students and communication and art students are likely to experience similar moments of anxiety and satisfaction during feedback. It is apparent, then, that questions such as whether faculty match the timing of their feedback with desired student changes and the extent to which students desire relational approaches bear significant implications for multiple areas of academia and deserve future study. Furthermore, the need to consider the feedback session as a complex communicative event that requires carefully crafted feedback derives from the understanding that context matters. For example, examining multiple disciplines, as well as multiple levels of education (foundational courses v. capstone courses), would provide an additional richness of understanding.

\section{Limitations}

Although this study extends FIT and FTM literature to include an examination of the use of such techniques in situ, the study is not without its limitations. For example, I focused on one landscape architecture class to allow for a deeper examination of the situation. However, other design courses could have added nuance or unexpected dynamics between students and faculty or professionals. Further, students in at a different educational level might possess better (or worse skills), allowing for the observation of different feedback strategies. The sample was fairly heterogeneous, and given the cultural influences on facework, having a more diverse sample (or samples from multiple institutions) could provide a more comprehensive examination. In addition to the limited sample, the coding approach that I employed could be considered a limitation, as I focused only on what the critics said. Other potentially meaningful areas of speakers' feedback might include their nonverbal behaviors as well as the ways that students interpreted speakers' messages and actions. Although I interpreted some messages as tactful in nature, it is possible that anxious recipients of such feedback could have interpreted the messages differently. Furthermore, 
FTM techniques may not have been successful based on individual student characteristics. However, this study's findings represent a balanced, considerate analysis of critic's feedback based on detailed operational definitions developed from previously successful research (Kerssen-Griep et al., 2003).

\section{Conclusion}

As revealed in previous research on feedback interventions (Smith \& King, 2004; Wang et al., 2008), indirect approaches to feedback potentially produce more positive affect in recipients. The results of this study, then, demonstrate that critics are aware of students' positive face needs and actively attempt to mitigate advice by relying heavily on informal language use. Professionals especially seemed to desire a safe and comfortable feedback environment for students, as they used 196 total FTM techniques, compared to 125 techniques used by faculty. Professionals' messages included more indirect techniques such as tactful hedges and complimentary language than faculty's messages. Although both faculty and professionals used high numbers of FTM techniques and informal language, it is apparent that professionals engaged in the most facework, perhaps due to a perceived viewpoint that they are "outsiders" who have not established appropriately strong connections with students in order to be directly critical of their work. Future research on feedback interventions should address the roles that outside professionals take, perhaps interviewing these faculty and professionals for better understanding of why they give (and do not give) specific kinds of advice.

Although informal language was the most prevalent FTM technique in this study, it is worth noting that students greatly value advice that is directly relevant and suggestive (Authors, 2011). Despite the positive nature of professionals' feedback, then, techniques such as complimentary language and tactful hedges might be problematic when they take the place of (or diminish the quality of) specific advice. Faculty members, however, offered more specific and direct advice, potentially indicating their understanding of what students desire from feedback interventions. As noted earlier, it is possible that faculty members are simply more comfortable with their students and therefore are more capable of providing specific (and sometimes negative) feedback. This study's findings also serve as evidence that informal language is a common FTM technique in college feedback interventions. Additionally, this study adds to the feedback literature by directly comparing feedback from professionals and university faculty, suggesting that faculty and professionals may serve different functions in feedback. Regardless of the specific course context, it is important to continue to research issues related to feedback ensure that students are not only comfortable but are also able to utilize the feedback.

Journal of the Scholarship of Teaching and Learning, Vol. 15, No. 4, August, 2015. 


\section{References}

Anthony, K. H. (1991). Design juries on trial: The Renaissance of the design studio. New York: Van Nostrand Reinhold.

Arundale, R. (2006). Face as relational and interactional: A communication framework for research on face, facework, and politeness. Journal of Politeness Research: Language, Behavior, Culture, 2, 193-216. doi:10.1515/PR.2006.011

Authors. (2008).

Authors. (2011).

Basey, J. M., Maines, A. P., \& Francis, C. D. (2014). Time efficiency, written feedback, and student achievement in inquiry-oriented biology labs. International Journal for the Scholarship of Teaching and Learning, 8(2). Retrieved from http://digitalcommons.georgiasouthern.edu/ijsotl/vol8/iss2/15

Brown, P., \& Levinson, S. (1987). Politeness: Some universals in language use. Cambridge: Cambridge University Press.

Burnett, R. (1996). “Some people weren't able to contribute anything but their technical knowledge": The anatomy of a dysfunctional team. In A. H. Duin \& C. J. Hansen (Eds.), Nonacademic writing: Social theory and technology, pp. 123-156. Mahwah, NJ: Lawrence Erlbaum.

Dannels, D P. (2000). Learning to be professional: Technical classroom discourse, practice, and professional identity construction. Journal of Business and Technical Communication, 14, 5-37. doi:10.1177/105065190001400101

Dannels, D. P., \& Norris Martin, K. (2008). Critiquing critiques: A genre analysis of feedback across novice to expert design studios. Journal of Business and Technical Communication, 22, 135-159.

Defazio, J., Jones, J., Tennant, F., \& Hook, S. A. (2010). Academic literacy: The importance and impact of writing across the curriculum-a case study. Journal of the Scholarship of Teaching and Learning, 10(2), 34-47.

Harrison, S., \& Barlow, J. (2009). Politeness strategies and advice-giving in an online arthritis workshop. Journal of Politeness Research: Language, Behavior, Culture, 5, 93-111. doi:10.1515/JPLR.2009.006

Hattie, J. \& Timperley, H. (2007). The power of feedback. Review of Educational Research, 77, 81-112. doi: 10.3102/003465430298487

Journal of the Scholarship of Teaching and Learning, Vol. 15, No. 4, August, 2015.

Josotl.Indiana.edu 
Kerssen-Griep, J. (2001). Teacher communication activities relevant to student motivation: Classroom facework and instructional communication competence. Communication Education, 50, 256-273. doi:10.1080/03634520109379252

Kerssen-Griep, J. Hess, J. A., \& Trees, A. R. (2003). Sustaining the desire to learn: Dimensions of perceived instructional facework related to student involvement and motivation to learn. Western Journal of Communication, 67, 357-381. doi:10.1080/10570310309374779

Kerssen-Griep, J., Trees, A. R., \& Hess, J. A. (2008). Attentive facework during instructional feedback: Key to perceiving mentorship and an optimal learning environment. Communication Education, 57, 312-332. doi:10.1080/03634520802027347

Kerssen-Griep, J., \& Witt, P. (2012). Instructional feedback II: How do instructor immediacy cues and facework tactics interact to predict student motivation and fairness perceptions? Communication Studies, 63, 498-517.

King, P. E., Schrodt, P., \& Weisel, J. J. (2009). The Instructional Feedback Orientation Scale: Conceptualizing and validating a new measure for assessing perceptions of instructional feedback. Communication Education, 58, 235-261. doi:10.1080/03634520802515705

King, P. E., \& Young, M. J. (2002). An information processing perspective on the efficacy of instructional feedback. American Communication Journal, 5. Retrieved from http:/www.acjournal.org/holdings/vol5/iss2/articles/feedback.pdf

King, P. E., Young, M. J., \& Behnke, R. R. (2000). Public speaking performance improvement as a function of information processing in immediate and delayed feedback interventions. Communication Education, 49, 365-374. doi:10.1080/03634520009379224

Kluger, A. N., \& DeNisi, A. (1996). The effects of feedback interventions on performance: A historical review, a meta-analysis, and a preliminary feedback intervention theory. Psychological Bulletin, 119, 254-284. doi:10.1037/0033-2909.119.2.254

Laybourn, P., Goldfinch, J., Graham, J., Macleod, L., \& Stewart, S. (2001). Measuring changes in groupworking skills in undergraduate students after employer involvement in group skill development. Assessment \& Evaluation in Higher Education, 26, 367-380.

Locher, M. A., \& Watts, R. J. (2005). Politeness theory and relational work. Journal of Politeness Research: Language, Behavior, Culture, 1, 9-33. doi:10.1515/jplr.2005.1.1.9

Luthans, F., \& Peterson, S. J. (2003). 360-degree feedback with systematic coaching: Empirical analysis suggests a winning combination. Human Research Management, 42(3), 243-256.

Merkin, R. S. (2006). Power distance and facework strategies. Journal of Intercultural Communication Research, 35, 139-160. doi:10.1080/17475750600909303

Journal of the Scholarship of Teaching and Learning, Vol. 15, No. 4, August, 2015. Josotl.Indiana.edu 
Oak, A. (2000). It's a nice idea, but it's not actually real: Assessing the objects and activities of design. International Journal of Art \& Design Education, 19, 86-95. doi:10.1111/14685949.00205

Oetzel, J., Ting-Toomey, S., Masumoto, T., Yokochi, Y., Pan, X., Takai, J., \& Wilcox, R. (2001). Face and facework in conflict: A cross-cultural comparison of China, Germany, Japan, and the United States. Communication Monographs, 68(3), 235-258.

Pickford, S. (2008). Dimensions of “vernacular” pedagogy. Language \& Education: An International Journal, 22, 48-61. doi:10.2167/le735.0

Price, M, Handley, K., Millar, J., \& O’Donovan, B. (2010). Feedback: All that effort, but what is the effect? Assessment \& Evaluation in Higher Education, 35, 277-89. doi: $10.1080 / 02602930903541007$

Smith, C. D., \& King, P. E. (2004). Student feedback sensitivity and the efficacy of feedback interventions in public speaking performance improvement. Communication Education, 53, 203216. doi:10.1080/0363452042000265152

Trees, A. R., Kerssen-Griep, J., \& Hess, J. A. (2009). Earning influence by communicating respect: Facework's contributions to effective instructional feedback. Communication Education, 58, 397416. doi: 10.1080/03634520802613419

Vásquez, C. (2009). Examining the role of face work in a workplace complaint narrative. Narrative Inquiry, 19, 259-279. doi:10.1075/ni.19.2.04vas

Wang, N., Johnson, W., Mayer, R. E., Rizzo, P., Shaw, E., \& Collins, H. (2008). The politeness effect: Pedagogical agents and learning outcomes. International Journal of Human-Computer Studies, 66, 98-112. doi:10.1016/j.ijhcs.2007.09.003

Wilson, S. R., Kim, M., \& Meischke, H. (1991). Evaluating Brown and Levinson's politeness theory: A revised analysis of directives and face. Research on Language \& Social Interaction, 25, 215-252. doi:10.1080/08351819109389363

Witt, P. L., \& Kerssen-Griep, J. (2011). Instructional feedback I: The interaction of facework and immediacy on students' perceptions of instructor credibility. Communication Education, 60, 7594. doi:10.1080/03634523.2010.507820 